\title{
Interactive comment on "Disaggregating surface change mechanisms of a rock glacier using terrestrial laser scanning point clouds acquired at different time scales" by Veit Ulrich et al.
}

\section{Anonymous Referee \#1}

Received and published: 28 July 2020

I welcome this contribution in an interesting area of research and in the authors have previous experience. I am open to clarifying my thoughts should this be needed, the comments are well-intended, to improve the paper and not all need to be addressed but please prioritise the points of clarification raised in particular.

\section{General comments:}

The manuscript is generally well-written and the quality is potentially acceptable but there are areas of clarification needed. The multi-directional change analysis is a key area for advancing change analysis processes but could be more clearly articulated, in the abstract and better developed in the discussion. 
Whilst the framing of the problem could be tightened up (for example, the approach presented still uses measured single values over specified time periods, which you describe as a limitation, you just add one period at higher frequency), there is value in the high temporal resolution scanning approach used, enabling disaggregation and directionality of longer term, more commonly applied annual frequency surveys. However, I cant help but feel that a simpler and much more significant addition would have been time-lapse camera imagery/photogrammetry (e.g. Blanch et al., 2020; doi:10.3390/rs12081240) over the annual period to achieve this much more comprehensively beyond a 3 week period. At the very least it would have been good to collect multiple surveys over the 3 week period to really explore the nature of the changes verses the LODs.

Links to drivers is stated as a key knowledge gap in the introduction but what were the main drivers of change over the monitored period and how discernible where they? 'individual precipitation events' (Line 54) for example or temperature variations are clearly needed to 'understand the processes operating over shorter times scales' as you state, so why have these not been used to interpret any of the changes in rates?

The fixed 3 week period (no scans in between) is extremely limited and hence prevents analysis of the surface dynamics beyond identifying that change in the different directions happens at different rates, as you would expect from a 3-dimensional deforming rock glacier surface. The final finding that ablation or downward movement is slightly higher in the warmth of July but the flow direction movement is inline with the annual average (Line 196) appears to be very intuitive. Perhaps the significance of the paper could helped by relating the spatial patterns to the drivers of change over this period as suggested in the introduction and the comment above, or by linking changes to the subsurface (you state only in the discussion at the end that there has been repeat GPR surveys - surely this would provide valuable context to the interpretation).

The interpretation of boulder movement is somewhat inconsistent. At the start of the paper they are framed as good indicators of flow direction (Line 64), then we see this

\section{ESurfD}

Interactive

comment
Printer-friendly version

Discussion paper

2 
is actually more complex with a range of directions and rates (e.g. Fig 5), presumably according to their local setting (near a slope edge or interacting with other boulders or topography), but then they are still used to infer flow movement after excluding the worst 8 boulders, when presumably all may be experiencing these complexities at smaller scales?

More detail is needed on the registration errors between scans within a dataset and then between datasets. With the generally small levels of changes occurring relative to the level of detection, and the potential for the majority of the scanning scene to be creeping, which will cause issues with any ICP alignment procedures, were independent checks on data registration accuracy carried out?

Linking back to my first point, I think the paper overplays the interpretation of annual data in places, which is clearly not suitable for interpretation of seasonality, nor is it typically used that way. The discussion of this 'finding' (lines $220-225$ ) is not reflective of how annual survey data are used and caution should be exercised in giving this impression. Essentially you are saying that to monitor seasonal changes you need appropriately timed surveys, not many would argue with this.

\section{Specific comments}

A clear definition of rock glaciers and their relation to debris covered glaciers for example would help.

Lines 52 - 59 need to be clarified, the implication that Zahs et al. (2019) found deformation processes occurred 'continuously' over a 12 year period is at odds with their data that showed: 'active and variable spatial and temporal surface dynamics'. Continuous movement over a 12 year period would indeed be surprising but this does not appear to be what was found, though I'm happy to be corrected by the author!

Line 60 - define 'short-interval', presumably it's application specific.

Line 61-63 the aim stated here is much clearer than in the abstract currently - consider 
developing this for the abstract.

Fig. 1. It's unclear what the 'three epochs of TLS point clouds' are? Provide dates, ESurfD as it is unclear how these relate to the changes claimed until later in the paper or switch the order and present it after line 84 and it possibly should be in the Methods section anyway. It is also unclear how you know the monitored 3 week period is one of 'heightened activity'? Is this written in retrospect or do you have more data and have selected this 3 week period as that of heightened relative activity?

Fig. 2 An inset map for context would help locate the study. Line 86: these three weeks were the only snow free conditions? Seems strange if so, and if not this does not justify why these three weeks (described in Fig. 1 as 'heightened activity').

Line 88: what were the ranges involved? Did you have to consider any range thresholds when combining the scans, what were the registration errors between scans and was the laser beam size at the maximum range relative to your sampling resolution? Was view angle/perspective (i.e. lots of very oblique measurements) an issue? These are potentially important points as you are calculating centroids of boulders - are you confident in the coverage and accuracy all around the used boulders? Are errors induced as a boulder turns, revealing a different geometry? A statement to clarifying specific error potential would help, how accurate/repeatable is the calculation of the centroids spatially across the rock glacier?

Fig. 3 Minor point, but it makes more sense to have the wider context and first survey done first - so I suggest swapping a and b around. Where is this profile on the slope? The movement of the boulder is intriguing, appearing to rise up and over a slope crest, is there an underlying ridge present? Some indication of the rock base would be very useful if available (I appreciate it may not but perhaps inferences could be made from the adjacent ridgelines). State 'Level of detection (LOD)' as you use it in the figure. (4) appears to be missing? Also I'm not sure Z - displacement is the correct title for the $\mathrm{Y}$-axis as you have expressly stated $\mathrm{M} 3 \mathrm{C} 2$ distance is not just in the $\mathrm{Z}$ direction, I

Interactive comment

Printer-friendly version

Discussion paper 
would advise this should just be 'Distance'.

Line 138 presumably the boulders were selected to represent and even coverage of ESurfD the site? Comment on their distribution.

Line 140 Do boulders not interact with each other complicating this simple flow parallel movement at the centimeter scale you are considering?

Interactive comment

Line 142 - 3 Clarify what is mean by 'The share of significant changes'

Line 148 The surface lowering is relatively more active in the 3 week period, but you also show the total amount of lowering is much lower that the amounts of accumulation - you detect mass accumulation and thickening overall, so caution should be exercised in the interpretation of these results, it might help to put these rates in absolute terms.

Line 149 what is the difference between 'rates made uniform over the year' and 'average across the year'? Furthermore, this assumption is clearly not appropriate for an alpine rock glacier which we would not expect to record uniform rates through a yearly cycle.

Fig. 4 The orientation of zones 1 and 2 are inverted and different to Fig. 2 making interpretation difficult - flow direction is now up the figure, you can work it out from the contours but it is not intuitive. Seems odd to put the map coordinate system extent int the caption but I presume this due to journal figure sizing restrictions.

Line $160-161$ This is rather confusing. As I understand it, your 'orographic left' would be the reader's right? In this area I cant see 'small and discrete areas of positive and negative change' that you infer as 'boulder movement' but rather large (nearly half of zone 1) coherent blocks of negative (upslope) and positive (downslope) change. The change is very patchy throughout the annual change, particularly on the margins, is this registration error between scans? It seems strange to have reversed patterns of change on either side of the slope with accretion high upslope and lowering downslope in patches on the left of image $4 b$ and the opposite in the right of zone 1 , more

Printer-friendly version

Discussion paper 
explanation is needed. Again perhaps combining with drivers of change or underlying bedrock might help.

ESurfD

Fig. 5 It would help to have similar lines in $5 \mathrm{c}$ denoting the glacier extent and zones to enable comparison with other figures. Not sure the hillshade background adds anything, why are the colored changes not shown to help interpretation? Why are we being shown different areas? Isn't the whole point to be able to interpret annual change better with the higher temporal resolution of the 3 week period? Therefore, we should be able to see what difference the higher frequency data make to the annual analysis.

Line 189 l'm not sure the movement data in 5 a are 'more homogenous', the directions seem to differ significantly, perhaps consider rephrasing around localised but coherent directions. It seems evident that independent boulder movement must have occurred but just haven't been detected, as you point out how difficult this is in the annual data in Fig. $3 b$ - it should be framed in this context rather than 'cannot assume they didn't'.

Line 193 What does a $0.10 \mathrm{~m}$ contribution to $-0.5 \mathrm{~m}$ actually mean? Do you mean a $-0.1 \mathrm{~m}$ contribution or did it offset the negative change by $0.1 \mathrm{~m}$ ?

Line 234 What do you mean by an 'increase in surface velocity'? Make sure it reconciles against the final line of the results 'movement was in-line with the annual average'.

Line 248 - 255 This is the first we hear of really valuable site data. It seems a shame that this was not introduced earlier and made much more use of. Surely it is relevant to the site context and selection of zones and then interpretation of results (note the comment above on Fig. 3 for example) - and much more could be made of the spatial patterns identified if better contextualised with this previous data.

Technical corrections

Printer-friendly version

Strictly speaking raster based change detection is not 2D as inferred in line 42-3, they are typically able to identify surface change in X, Y, and Z directions, and should probably be referred to as $2.5 \mathrm{D}$ to distinguish from full $3 \mathrm{D}$ analysis because the $\mathrm{z}$ component

Interactive comment 
is assumed normal to the raster $X, Y$ grid (as noted in Williams et al., 2018).

Line 67: Reword 'This will enable to disclose' to better grammar.

ESurfD

Line 142 correct: $0.11^{\circ} \mathrm{m}$

Line 171 'move creep-induced' needs rephrasing

Fig 5 . Is boulder 9 the same boulder in both subsections? Presumably not so perhaps 6 is upside down?

Line 268 Should read 'at a sub-monthly interval' as you on used one three-week period.

Interactive comment on Earth Surf. Dynam. Discuss., https://doi.org/10.5194/esurf-2020-55, 2020. 